\title{
State of Prooxidant and Antioxidant Blood System in Albino Rats under Joint Effect of T-2 Toxin and Salmonellae in the Experiment
}

\author{
S.V. Shabunin, A.G. Shakhov*, G.A. Vostroilova, L.Yu. Sashnina, G.N. Bliznetsova \\ State Scientific Institution "All-Russian Veterinary Research Institute of Pathology, Pharmacology and Therapy" \\ of the Russian Academy of Agricultural Sciences, Voronezh, Russia \\ *State Scientific Institution "All-Russian Veterinary Research Institute of Pathology, Pharmacology, and \\ Therapy" of the Russian Academy of Agriculture Sciences,Voronezh, Russia. \\ E-mail: gvostroilova@mail.ru
}

\begin{abstract}
Current experimental research on albino rats has studied the effect of salmonellae and T2 toxin on indices of lipid peroxidation (LPO) and antioxidant protection. Joint effect of bacteria and toxicant, especially in a dose of $560.0 \mathrm{\mu g} / \mathrm{kg}$, was characterized by a more evident increase of integral index of blood and liver LPO - malonic dialdehyde (MDA) by 1.7 and 4.4 times, respectively, and also by exhaustion of antioxidant system (AOS) in animals' organisms comparing with the situation when the animals were separately contaminated. That was proved by the decrease of catalase activity by $24.7 \%$ and vitamin E content - by $43.6 \%$ in them. The results obtained demonstrated that salmonella infection against the background of intoxication with T-2 toxin significantly disturbed prooxidant-antioxidant balance in the organism that was the most important mechanism for the oxidative stress development.
\end{abstract}

Keywords. Lipid peroxidation, malonic dialdehyde, antioxidant system, catalase, glutathione peroxidase, vitamins A and E, T-2 toxicosis, salmonellosis, albino rats.

\section{Introduction}

Enteric infections in animals, caused by potentially pathogenic bacteria, are widely spread at modern factory farms (S.I. Dzhupina, 2002; H.Z. Gaffarov, E.A. Romanov et al., 2003). They often occur against the background of feed toxicoses and first of all mycotoxicoses (A.V. Ivanov et al., 2010; V. Vandenbroucke, 2011, 2012).

One of the main places among diseases is occupied by salmonellosis (M.A. Sidorov et al., 1991; V.V. Subbotin et al., 2006; A.G. Shakhov et al., 2008).

On the one hand, pathogenesis of many infectious diseases is determined by antigenic and pathogenic properties of infectious agent, on the other hand, by immune, metabolic and antioxidant status of microorganism (M.Ya. Malakhova, 2000; V.H. Havinson et al., 2003; A.G. Shakhov, 2004; N.P. Chesnokova, 2006; V.I. Kuznetsov, 2007; N.N. Martynova, 2007; V.F. Pavelkina et al., 2012, 2014; A.G. Shakhov et al., 2015; Martins P.S. et al., 2003; Gilca M. et al., 2007; Nguyen H.X. et al., 2007; Papatheodorou L. et al., 2007).

Convincing data, proving significance of lipid peroxidation (LPO) activation in pathogenesis of bacterial infections and particularly salmonellosis, have been accumulated by now (L.D. Martynenko, A.P. Shepelev, 1990; L.B. Okonenko, 1994; L.V. Oleynik et al., 2004; Z.A. Kambachokova, 2006; V.I. Kuznetsov, 2007; B.S. Nagoev et al., 2008 et al.). The studies of L.V. Oleynik et al. (2004), Z.A. Kambachokova (2006), B.S. Nagoev, Z.A. Kambachokova (2006) et al. demonstrated that increased blood level of malonic dialdehyde (MDA) was registered in animals and humans even at early stages of salmonellosis development. At the same time a direct dependence between the intensity of LPO processes and clinical presentations of pathological process under experimental salmonella infection was detected in animals (L.V. Oleynik et al., 2004).

It is also stated that intoxication of animals with T-2 toxin is accompanied by activation of lipid peroxidation (N.P. Golovchak et al., 2006; A.V. Ivanov et al., 2010; E.Yu. Tarasova, 2010; A.G. 
Shakhov et al., 2016; Leeson et al., 1995; D. Hoehler et al., 1996, 1998; J.E. Dvorska and P.F. Surai, 2001).

Excessive accumulation of free radicals destroys permeability, structure and functions of biomembranes, lipid, protein and nucleic acid metabolism, decreases natural resistance, humoral and cellular specific and nonspecific immunity (D.Yu. Egorov, A.V. Kozlov, 1988; M.A. Ryzhikova, 2001; G.N. Kryzhanovskiy, 2002; M.I. Retskiy et al., 2002; A.S. Kashin et al., 2003; L.V. Oleynik et al., 2004).

Joint effect of various pathogenic factors on animals registered at factory farms manifests itself by activation of LPO processes and depression of antioxidant protection (AOP) and arouses great interest.

\section{The Aim of the Research}

Studying prooxidant and antioxidant blood system in albino rats under experimental salmonellosis without preliminary intoxication with T-2 toxin and against its background.

\section{Materials and Methods}

\subsection{Experiment Scheme}

The experiments were realized on healthy pubescent nonlinear albino rats weighted 230-150g which were kept in vivarium of SSI "All-Russian Veterinary Research Institute of Pathology, Pharmacology and Therapy" of the Russian Academy of Agricultural Sciences according to SC 2.2.1.3218-14 and rules accepted by European Convention for the Protection of Vertebrate Animals used for Experimental and other Scientific Purposes (Strasbourg, 1986). Keeping, feeding, care and removal of animals from the experiment were realized in accordance with the requirements of "The Rules on Execution of Works with the Use of Experimental Animals" and "The Principles of Good Laboratory Practice".

Control (intact) and trial groups were randomly formed out of male individuals according to body weight. The animals were under quarantine with standard dietary intake during two weeks before the experiment.

Four groups of albino rats $(n=12)$ were formed for the trial. Group I - control (intact). Animals of groups III and IV were consuming T-2 toxin with feed in doses of $1 / 20 \mathrm{LD}_{50}(140.0 \mathrm{\mu g} / \mathrm{kg})$ and $1 / 5 \mathrm{LD}_{50}$ $(560.0 \mu \mathrm{g} / \mathrm{kg})$ during 6 days. Animals of groups II, III and IV were intraperitoneally infected in twentyfour hours after subacute intoxication with a day culture of Salmonella cholerae suis in a dose of 1.9 billion microcells $\left(\mathrm{LD}_{50}\right)$. Then they were clinically observed during 6 days. Morbidity, symptom complex and mortality were registered. Animals of control and trial groups were tested for lipid peroxidation and antioxidant protection system indices on the $7^{\text {th }}$ day. Intensity of LPO reactions was evaluated according to the accumulation of malonic dialdehyde in blood and liver and AOPS - according to the activity of glutathione peroxidase, catalase and blood concentration of vitamins $\mathrm{A}$ and $\mathrm{E}$ in albino rats.

The researches were realized in accordance with Guidance manual (M.I. Retskiy et al., 2010) and user instruction manuals for the devices.

\subsection{Equipment and Reagents}

Spectrophotometer Shimadzu UV-1700 (Shimadzu, Japan), analytical balance ALC-210d4 (Acculab, USA), refrigerated laboratory centrifuge Durafuge 300 R (Jouan S.A.S., France), the ionomer HannapH 213 (Hanna, Germany), ultraviolet lamp of PRK-4 (Russia).

Ammonium molybdate (Sigma, USA), potassium phosphate monobasic $\left(\mathrm{KH}_{2} \mathrm{PO}_{4}\right)$, analytical grade for analysis (Sigma, USA), potassium phosphate dibasic $\left(\mathrm{K}_{2} \mathrm{HPO}_{4}\right)$, analytical grade for analysis (Sigma, USA), potassium hydroxide (Sigma, USA), ferric (III) chloride (Merck, Germany), 1,10-Phenanthroline (OP) (Sigma, USA), disodium ethylenediaminetetraacetate dehydrate (EDTA-Na) (Prolabo, France), standard sample $\alpha$-tocopherol (Sigma, USA), methanol analytical grade (Merck, Germany), Glutathione reduced, 98\%, for analysis (Acros organics, USA), 5,5-Dithiobis-(2-nitrobenzoic acid), 99\% (Acros organics, USA), 2-thiobarbituric acid (2-TBA) (Sigma, USA), trichloroacetic acid, (Sigma, USA), 
hexane, analytical grade for analysis (Panreac, Spain), benzene, xylene, (Sigma, USA), octane, (Merck, Germany).

\subsection{Detection of Malonic Dialdehyde}

MDA reacts with 2-thiobarbituric acid at high temperature in acid environment with the formation of stained three-methotype complex (TMC) possessing the maximum absorption of $532 \mathrm{~nm}$.

To evaluate MDA blood content, $2.5 \mathrm{ml}$ of $10 \%$ trichloroacetic acid was added to $2.5 \mathrm{ml}$ of heparinized blood, thoroughly agitated and centrifuged (15 minutes, $3000 \mathrm{rpm}) .3 .0 \mathrm{ml}$ of centrifugate was carried into clean centrifuge tubes and $1.5 \mathrm{ml}$ of $0.8 \%$ 2-thiobarbituric acid was added to it, thoroughly agitated and placed into boiling water bath for $15 \mathrm{~min}$. Then samples were cooled and centrifuged (5 minutes, $3000 \mathrm{rpm}$ ). Optical density was measured on spectrophotometer at $\lambda=532 \mathrm{~nm}$ relatively to control sample, that contained $2.5 \mathrm{ml}$ of distilled water, which was processed in the same way as trial samples. To prepare homogenate, liver samples were homogenized at $4{ }^{\circ} \mathrm{C}$ and slurried in 9 volumes of $0.25 \mathrm{M}$ of saccharose solution with $0.001 \mathrm{M}$ EDTA, $\mathrm{pH}$ 7.4. Centrifugation was realized under cooling during $3 \mathrm{~min}$ at $1000 \mathrm{rpm}$. Supernatant part of liver homogenate was used to determine MDA content as it was mentioned above. Malonic dialdehyde content was calculated by the formula (1).

$$
C=E \times 10^{6} \times 3 / 1.56 \times 10^{5}
$$

where $\mathrm{C}$ - malonic dialdehyde concentration, $\mu \mathrm{mol} / \mathrm{L}$;

$\mathrm{E}$ - optical density of the sample;

$10^{6}$ - conversion rate into $\mu \mathrm{mol} / \mathrm{L}$;

$1.56 \times 10^{5}$ - molar extinction coefficient TMC MDA with 2-TBA;

3 - dilution factor

\subsection{Detection of Catalase and Glutathione Peroxidase Activity}

To determine catalase and glutathione peroxidase activity, basal hemolysate was obtained by adding 3.5 $\mathrm{ml}$ of distilled $\mathrm{H}_{2} \mathrm{O}$ (preliminary held for 10 minutes at room temperature) to $0.5 \mathrm{ml}$ of heparinized blood.

\subsection{Detection of Catalase Activity}

To determine catalase activity, working hemolysate was obtained by the dilution of basal one with distilled $\mathrm{H}_{2} \mathrm{O}\left(0.2 \mathrm{ml}\right.$ of basal hemolysate $+3.8 \mathrm{ml}$ of distilled $\left.\mathrm{H}_{2} \mathrm{O}\right) .2 .0 \mathrm{ml}$ of buffer substrate, containing Tris-HCL buffer and hydrogen peroxide, were added into all trial and control tubes, then incubated for 10 minutes at $37{ }^{\circ} \mathrm{C} .0 .1 \mathrm{ml}$ of working hemolysate was added into trial tubes, agitated and incubated for 3 minutes at $37^{\circ} \mathrm{C}$. Reaction was stopped by adding $2.0 \mathrm{ml}$ of $4.5 \%$ of ammonium molybdate into trial tubes. $2.0 \mathrm{ml}$ of $4.5 \%$ of ammonium molybdate was added into control tubes and then into $1.0 \mathrm{ml}$ of working hemolysate. Optical density of trial and control samples was measured spectrophotometrically at $\lambda=410 \mathrm{~nm}$ relatively to comparison solution, that contained $1 \mathrm{ml}$ of $0.1 \mathrm{M}$ Tris-HCL buffer ( $\mathrm{pH} 7.4$ ), $3 \mathrm{ml}$ of distilled water and $0.1 \mathrm{ml}$ of working hemolysate. Catalase activity was calculated by the formula (2).

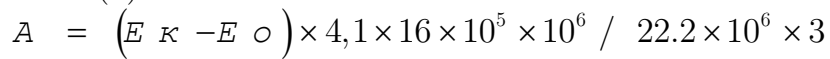

where A - enzyme activity, M.U. ( $\mu$ mol $\left.\mathrm{H}_{2} \mathrm{O}_{2} / \mathrm{L} \times \min \right)$;

$\mathrm{EK}$ - optical density of the control sample;

Eo - optical density of the test sample;

4.1 - final volume of the sample;

$16 \times 10^{5}$ - dilution factor;

$10^{6}$ - conversion rate of mmol into $\mu \mathrm{mol}$;

$22.2 \times 10^{6}$ - molar extinction coefficient of $\mathrm{H}_{2} \mathrm{O}_{2}$;

3 - incubation time, min

\subsection{Detection of Glutathione Peroxidase Activit}

To determine glutathione peroxidase blood activity, $1 \mathrm{ml}$ of glutathione and $1 \mathrm{ml}$ of basal hemolysate 
were added into tubes. $0.5 \mathrm{ml}$ of mixture was added into trial and control tubes and incubated for 5 minutes at $37^{\circ} \mathrm{C}$. $0.1 \mathrm{ml}$ of hydrogen peroxide solution was added into trial tubes, then agitated and incubated for 1 minute at $37^{\circ} \mathrm{C} .2 \mathrm{ml}$ of $10 \%$ TCA was added into tubes after incubation and $0.1 \mathrm{ml}$ of hydrogen peroxide was added into control tubes after it, then thoroughly agitated and placed into refrigerator for 10 minutes. Samples were centrifuged under cooling $\left(0-4^{0} \mathrm{C}\right)$ for 15 minutes at $3000 \mathrm{rpm}$. Then $0.5 \mathrm{ml}$ of supernatant from trial and control tubes were added into tubes, that contained $10 \mathrm{ml}$ of phosphate buffer ( $\mathrm{pH} 8.0$ ), and $0.05 \mathrm{ml}$ of Ehrlich's reagent was added into each tube and agitated. Optical density of trial and control samples was measured spectrophotometrically at $\lambda=412 \mathrm{~nm}$. To determine the rate of nonenzymatic oxidation of reduced glutathione, $1 \mathrm{ml}$ of distilled water was used instead of $1 \mathrm{ml}$ of hemolysate. Activity of blood glutathione peroxidase was calculated by the formula (3).

$$
A=(E \circ-E K) \times 10.55 \times 10^{6} \times 166.4 / 13100
$$

A - enzyme activity in $\mu$ mol of reduced glutathione / $(\mathrm{L} \times \mathrm{min})$;

EO - optical density of the control sample comparing with the trial one at enzymatic oxidation of glutathione;

EK - optical density of the control sample comparing with the trial one at nonenzymatic oxidation of glutathione;

10.55 - final volume of the sample, $\mathrm{ml}$;

166.4 - dilution factor;

$10^{6}$ - conversion rate of mmol into $\mu \mathrm{mol}$;

13100 - molar extinction coefficient of TN PA

\subsection{Detection of Vitamin E}

Method for determination of $\alpha$-tocopherol (vitamin $\mathrm{E}$ ) was based on determining $\mathrm{F}^{2+}$ ions, forming under interaction of vitamin $\mathrm{E}$ with ferric chloride $\left(\mathrm{F}^{3+}\right)$, in a form of stained $\mathrm{F}^{2+}$ complex with orthoPhenantrolin (OP) or batho-Phenantrolin (BP).

$1 \mathrm{ml}$ of blood serum was added into all tubes with plug stoppers and $1 \mathrm{ml}$ of ethanol was poured, thoroughly agitated and then $3 \mathrm{ml}$ of hexane were extracted for 5 minutes. Then it was centrifuged for 10 minutes at $3000 \mathrm{rpm} .2 \mathrm{ml}$ of hexane fraction were evaporated in nitrogen flow at temperature not higher than $50^{\circ} \mathrm{C}$, residue was dissolved in $1 \mathrm{ml}$ of benzol, $1 \mathrm{ml}$ of $0.025 \%$ ferric chloride solution was added into each tube and kept for 5 minutes at room temperature. Then $1 \mathrm{ml}$ of $0.05 \%$ solution of OP or BP was poured into samples and in 2 minutes measured spectrophotometrically at $\lambda=510 \mathrm{~nm}$ (OP) or $\lambda=535 \mathrm{~nm}$ (BP) relatively to the sample that contained $1 \mathrm{ml}$ of benzol and $2 \mathrm{ml}$ of ethanol. Measurements were realized on the basis of calibration using $\alpha$ - tocopherol as a standard sample. Vitamin E blood serum concentration was calculated by the formula (4).

$$
C=A \times 3 / 2
$$

where $\mathrm{C}$ - blood serum content of vitamin E, $\mu \mathrm{mol} / \mathrm{L}$;

A - amount of vitamin $\mathrm{E}$ according to calibration curve;

3 - total amount of hexane extract;

2 - volume of evaporated hexane extract

\subsection{Detection of Vitamin A}

Method for determination of vitamin A was based on alkaline hydrolysis with the use of potassium hydroxide solution in ethanol, extraction of low-volatile organic solvents and further spectrophotometry before and after its destruction with ultraviolet rays.

$1 \mathrm{ml}$ of blood serum was added into each tube with plug stopper and poured $1 \mathrm{ml}$ of $1 \mathrm{H}$ potassium hydroxide solution in ethanol, thoroughly agitated. Hydrolysis was realized on a water bath (at $60^{\circ} \mathrm{C}, 20$ minutes), then tubes were cooled and $3 \mathrm{ml}$ of xylol-octane mixture (1:1) were extracted for 3 minutes. Then it was centrifuged for 5 minutes at $1500 \mathrm{rpm}$. Vitamin A detection was realized by twofold spectrophotometrical measurement $(\lambda=328 \mathrm{~nm})$ before and after irradiation of samples with ultraviolet rays. Vitamin A concentration was calculated by the formula (5).

$$
C=6.37 \times\left(E_{1}-E_{2}\right) \times 3 \times 3.491
$$


where vitamin A blood serum content, $\mu \mathrm{mol} / \mathrm{L}$;

6.37 - coefficient for vitamin A according to Bessey;

$\mathrm{E} 1$ - optical density of vitamin A solution before exposure to radiation at $\lambda=328 \mathrm{~nm}$;

$\mathrm{E} 2$ - optical density of vitamin A solution after exposure to radiation at $\lambda=328 \mathrm{~nm}$;

3 - dilution factor;

3.491 - conversion rate into $\mu \mathrm{mol} / \mathrm{L}$

Determination of $\mathrm{LD}_{50}$ salmonellae and death specificity of animals was realized by standard bacteriological methods.

\subsection{Statistical Analysis}

Statistical manipulation of data obtained was realized with the use of program Statistica v6.1, certainty value - according to Student's criterion (V.I. Yunkerov, S.G. Grigoryev, 2002).

\section{$4 \quad$ Results and Discussion}

\subsection{Clinical Studies}

Clinical signs of salmonella infection without preliminary intoxication with T-2 toxin were registered in $66.6 \%$ of animals and in $83.3 \%$ (toxin dose of $140.0 \mu \mathrm{gg} / \mathrm{kg}$ ) and $100.0 \%(560.0 \mu \mathrm{pg} / \mathrm{kg}$ ) against its background. The last was characterized by the decrease of appetite and response to exogenous irritants, depression of motion activity, disheveled coat, crowding, shapeless faeces and profuse diarrhea in some animals. At the same time their body weight decreased by $9.0,13.8$ and $20.7 \%$ and death was $16.7,25.0$ and $41.7 \%$, respectively.

\subsection{The Effect of Salmonellosis on LPO and AOS Indices}

The intensification of LPO processes under salmonella infection was proved by the increase of its secondary MDA product content in blood plasma and liver by 2.6 and 3 times, respectively, in comparison with the same ones in rats of control group (table 1).

Table 1. The state of prooxidant system in albino rats under salmonella infection without preliminary intoxication with T-2 toxin and against its background.

\begin{tabular}{c|c|c}
\hline \multirow{2}{*}{ Group } & \multicolumn{2}{|c}{ MDA, $\mu \mathrm{mol} / \mathrm{L} / \mathrm{g}$} \\
\cline { 2 - 3 } & blood & liver \\
\hline I (control) & $1.14 \pm 0.05$ & $1.46 \pm 0.15$ \\
\hline II & $2.95 \pm 0.06^{*}$ & $4.45 \pm 0.59^{*}$ \\
\hline III & $4.77 \pm 0.06^{*}$ & $16.39 \pm 2.05^{*}$ \\
\hline IV & $5.07 \pm 0.08^{*}$ & $19.73 \pm 1.03^{*}$ \\
\hline
\end{tabular}

The infection of animals with salmonellae had a negative effect on their antioxidant protection (table 2 ) that was proved by significant decrease of catalase enzyme activity by $24.8 \%$, which catalyzed decomposition of hydrogen peroxide into water and molecular oxygen, blood plasma vitamin E content by $39.1 \%$, that regulated the intensity of free-radical reactions in cells and interrupted oxidation chain, and also vitamin A by 4.1 times, that could be a "trap" for free radicals, singlet oxygen and reductant of sulfhydryl compounds (A.A. Ryzhov et al., 2007).

The activity increase of selenium-containing GPO enzyme by $16.0 \%$ was registered in animals of this group. Selenium-containing GPO enzyme, catalyzing hydrogen peroxide and organic peroxides transformation into hydro-compounds, which then can be metabolized by cellular systems, evidently has a compensatory character, preventing the development of blood cells membrane structure disorganization. 
Thus, the changes both in enzymatic and nonenzymatic link of antioxidant protection of the organism prove its insufficiency in albino rats under the action of salmonellae.

Table 2. Activity of enzymatic and nonezymatic link of antioxidant protection in albino rats under salmonella infection without preliminary intoxication with T-2 toxin and against its background.

\begin{tabular}{|c|c|c|c|c|}
\hline \multirow[t]{2}{*}{ Group } & \multicolumn{4}{|c|}{ Indices } \\
\hline & $\mathrm{GPO}, \mu \mathrm{mol} \mathrm{RG} / \mathrm{L} \times \min \times 10^{3}$ & $\begin{array}{c}\text { Catalase, } \\
\mu \mathrm{mol} \mathrm{H}_{2} \mathrm{O}_{2} / \times \min \times 10^{3}\end{array}$ & $\begin{array}{c}\text { Vitamin A, } \\
\mu \mathrm{mol} / \mathrm{L}\end{array}$ & Vitamin E, $\mu \mathrm{mol} / \mathrm{L}$ \\
\hline I (control) & $9.74 \pm 0.74$ & $28.6 \pm 1.32$ & $11.9 \pm 0.77$ & $19.2 \pm 1.40$ \\
\hline II & $11.3 \pm 0.45$ & $21.5 \pm 0.39^{*}$ & $2.89 \pm 0.04^{*}$ & $11.7 \pm 0.85^{*}$ \\
\hline III & $11.1 \pm 0.85$ & $18.6 \pm 1.08^{*}$ & $3.89 \pm 0.13^{*}$ & $11.5 \pm 1.21^{*}$ \\
\hline IV & $11.8 \pm 0.35^{*}$ & $16.2 \pm 1.66^{*}$ & $3.57 \pm 0.23^{*}$ & $6.60 \pm 0.58^{*}$ \\
\hline
\end{tabular}

\subsection{The Effect of Salmonellosis and T-2 Toxin on LPO and AOS Indices}

The infection of animals with salmonellae against the background of intoxication with T-2 toxin was accompanied by a more significant increase of MDA content in blood - by 4.2 times and liver - by 11.2 $(140.0 \mu \mathrm{g} / \mathrm{kg}), 4.4$ and 13.5 times $(560.0 \mu \mathrm{g} / \mathrm{kg})$.

Salmonella infection against the background of preliminary intoxication promoted a more intensive decrease of catalase activity by $35.0(140.0 \mu \mathrm{g} / \mathrm{kg})$ and $43.4 \%(560.0 \mu \mathrm{g} / \mathrm{kg})$, protecting the cells from the action of active forms of oxygen and also from the increase of GPO activity by 14.0 and $21.1 \%$, respectively (table 2), necessary for the restraining the process of blood cells membrane structure disorganization.

Infection of albino rats with salmonellae against the background of intoxication with T-2 toxin caused the depression of functional activity of nonenzymatic link of antioxidant system that was proved by the decrease of blood plasma level of vitamins $\mathrm{E}$ and A by 40.1 and $67.3 \%(140.0 \mu \mathrm{g} / \mathrm{kg})$ and by 65.6 and $70.0 \%(560.0 \mu \mathrm{g} / \mathrm{kg})$.

Thus, the changes registered both in enzymatic and nonenzymatic links of antioxidant system prove a more significant exhaustion of antioxidant system in rats' organisms under the action of joint effect of T-2 toxin and salmonellae.

\subsection{Discussion}

Salmonella infection without preliminary intoxication caused evident intensification of free radical processes. At the same time the activity of antiradical protection system appeared insufficient for the maintenance of balance in LPO-AOP system that was proved by LPO product accumulation.

Active chemotaxis of neutrophils into the nidus of inflammation, where they by absorption and digestion of foreign agents change their metabolic activity, characterized by oxygen absorption and hyperproduction of active forms of oxygen (AFO), is realized under the development of salmonella infection. Incorporation of oxygen into molecules of oxidized substrate leads to the formation of free radicals, hydroperoxides, which then cause damage of proteins, nucleic acids, inactivate most enzymes, change structural-functional state of biomembranes and thereby lead to the disorders of various metabolic links, depression of cellular and humoral links of immunity (L.B. Okonenko, 1994, A.M. Zemskov et al., 2013).

It is stated that excessive formation of free radicals and oxidative stress are the main mechanisms of T-2 toxin toxic effect (P.F. Surai, 2006). Mycotoxins and particularly T-2 toxin are considered as the most important stress factors of feed origin, disturbing the balance between prooxidants and antioxidants in the organisms. This balance is responsible for the regulation of many important metabolic processes, providing immunocompetence, growth, development and protection of animals and poultry from various adverse effects in the conditions of industrial production. When organism's adaptive possibilities are exhausted as a result of action of T-2 toxin, acute oxidative stress or low antioxidant protection, caused by problems in feeding animals and poultry, the process becomes 
uncontrollable and concludes with apoptosis of many cells. Firstly, the activity of enzymes, participating in T-2 toxin detoxication and intensifying its toxicity, begins. Then mitochondrion membrane disturbance begins, particularly the loss of potential that in turn leads to the disorders of electron transport chain in mitochondria and electron leakage considerably increases, significantly increasing free radical formation and providing profound oxidative stress. The loss of redox potential of cells leads to apoptosis. At the same time it is generally acknowledged that free radicals damage immune cell receptors. Thus, this process is an immunosuppression (V.I. Fisinin, P. Surai, 2012).

Our earlier researches devoted to studying prooxidant-antioxidant status of cytokine profile in albino rats under experimental T-2 toxicosis $(140.0$ and $560.0 \mu \mathrm{g} / \mathrm{kg}$ ) and their correlation (A.G. Shakhov et al., 2016) stated dose-dependent action of MDA accumulation in blood and liver, connected with catalase inhibition and blood concentration decrease of nonenzymatic antioxidants. It is shown that pathogenic effects of T-2 toxin are in vivo connected with an intensification of active forms of oxygen production and LPO toxic products accumulation in blood that leads to the disorders of cytokine synthesis by immune cells, damage of their biomembranes and probably to apoptosis. These processes are reflected in imbalance of immunocyte populations and cytokines produced by them that has an adverse effect on organisms' resistance to pathogens.

The most evident changes of prooxidant-antioxidant status are registered in animals infected with salmonellae against the background of intoxication with T-2 toxin which are determined by their synergism.

The stated capacity of xenobiotic and salmonellae to activate the processes of free radical oxidation can be evaluated as an important mechanism of their cytotoxicity, determining stated structural and functional changes of immune system under their joint effect. This mechanism is activated from certain threshold level of active forms of oxygen. At the same time mobilization of cell protective systems weakens that plays a significant role in cellular exhaustion of organs of immunogenesis system and development of immunosuppression.

The researches of M.I. Retskiy et al. (2002) demonstrated that the disorders in mononuclear phagocyte-macrophage system occurred under accumulation of highly active products of free radical oxidation in the organism. These disorders were connected with the depression of their functions as a result of structure disorders of phagocyte cellular membranes. The researches also demonstrated modifying effect of LPO secondary products on molecular structure of circulating nonspecific humoral factors of the immunity, possessing protein nature, and the mechanism of which is in a varying degree determined by their enzymatic activity.

Our earlier researches (A.G. Shakhov et al., 2016) stated that infection of albino rats with salmonellae (1.9 billion microcells) against the background of T-2 toxicosis $(140.0$ and $560 \mu \mathrm{g} / \mathrm{kg}$ ) was accompanied by a more significant concentration increase of proinflammatory cytokine IL-1 $\beta$ and level decrease of cytokine IL-2, stimulating cellular immunity, immunoregulatory mediator $\gamma$-INF and also antiinflammatory cytokine IL-10, proving the suppression of T-cell function (Th-1 in Th-2, respectively) by pathogens, produced by them in comparison with the case when pathogens were prescribed separately. At the same time a more significant decrease of $\gamma$-INF number and $\gamma$-INF/IL-4 ratio was detected under infection of animals with salmonellae against the background of intoxication with a high dose of toxicant that proved an evident T-deficit and a more significant suppression of Th-1 lymphocyte function.

\section{Conclusions}

The results of the research and scientific literature data prove that salmonellosis without preliminary intoxication with T-2 toxin and especially against its background causes evident intensification of free radical processes and exhaustion of antioxidant system in animals that can be evaluated as a significant mechanism of their cytotoxicity, determining structural and functional changes of immune system.

Acknowledgments. We acknowledge Federal Agency for Scientific Organizations of the Russian Federation for the financial support and FSBSI "Federal Center for Toxicological, Radiation and Biological Safety" (Kazan, Russia) for the provision of T-2 toxin sample. 


\section{References}

1. Activation of free radical oxidation is an effective link of typical pathological processes (in Russian) / [N.P. Chesnokova et al.; general editorship N.P. Chesnokova, M.Yu. Ledvanov. - Saratov: Publishing house of Saratov State Medical University, 2006.

2. H.Z. Gaffarov, E.A. Romanov, Infectious diseases of pigs and modern methods for controlling them (in Russian). - Kazan: RITS School; Co Ltd. The sixth element, 2003.

3. N.P. Golovcjak, A.V. Tarnovska, G.I. Kotsyumbas, D.I. Sanagurskiy, "The number of diene conjugates in various parts of the brains in piglets under the effect of T-2 toxin" (in Russian), Journal of Experimental and clinical physiology and biochemistry, no. 3, pp. 33-36, 2006.

4. SS 33044-2014. The Principles of Good Laboratory Practice (in Russian).

5. S.I. Dzhupina, "Etiology and prophylaxis of mass gastrointestinal diseases in calves" (in Russian), in Actual problems of diseases of young animals in modern conditions, 2002. Proceedings. The International Scientific and Practical Conference. Voronezh, 2002, pp. 8-11.

6. D.Yu. Egorov, A.V. Kozlov, The nature of LPO products determined in blood serum according to the reaction with 2-thiobarbituric acid (in Russian) / Deposited in VINITI 30.08.88. - No. 6766. - B-88. - Moscow, 1988.

7. Zemskov A.M. "Encyclopaedia of immunology" (in Russian). Edited by prof. A.M. Zemskov, prof. V.M. Zemskov, academician of the RAS, RAMS, prof. V.A. Chereshnev, M.: Triada-X, Vol. 1, 2013.

8. Z.A. Kambachokova The state of prooxidant and antioxidant blood system in the ill with food toxicoinfection and salmonellosis: abstract of a thesis, candidate of medical sciences (in Russian), Nalchik, 2006.

9.Z.A. Kambachokova, "The Level of malonic dialdehyde in the dynamics in the ill with salmonellosis" (in Russian) in Infectious diseases: problem of public health and military medicine, 2006. Proceedings. Russian Scientific and Practical Conference. Saint-Petersburg, 2006, p. 142.

10.A.S. Kashin, A.P. Grechkin, K.V. Vorobyev, "Anthropogenic ecological diseases of the calves (prophylaxis and treatment)" (in Russian), Journal of Veterinariya, no. 2, pp. 37-42, 2003.

11.G.N. Kryzhanovskiy, "Dysregulation pathology" (in Russian), Journal of Pathological physiology and experimental therapy, no. 3, pp. 2-19, 2002.

12.Kuznetsov V.I. The role of disturbances of lipid metabolism and processes of free radical oxidation in pathogenesis and clinical picture of some infectious diseases (in Russian): abstract of a thesis, doctor of medical sciences, Saratov, 2007.

13.M.Ya. Malakhova, "Endogenous intoxication as a reflection of compensatory rearrangement of metabolic processes in the organism" (in Russian), Journal of Effective therapy, no. 4, pp. 3-14, 2000.

14.L.D. Martynenko, A.P. Shepelev, "Lipid peroxidation under experimental salmonella infection" (in Russian), Journal of Microbiology and Epidemiology, no. 4, pp. 7-10, 1990.

15.N.N. Martynova Clinico-pathogenetic significance of proinflammatory cytokines (IL-1 , IL-6 and TNF- ) and anti-inflammatory interleukin-10 in the ill with salmonellosis and acute shigellosis: abstract of a thesis, candidate of medical sciences (in Russian), Moscow, 2007.

16.A.V. Ivanov, V.I. Fisinin, M.Ya. Tremasov, K.H. Papunidi, Mycotoxicoses (biological and veterinary aspects): monograph (in Russian), Moscow, 2010.

17.B.S. Nagoev, Z.A. Kambachokova, "Content of malonic dialdehyde and ceruloplasmin in blood plasma in the ill with salmonellosis" (in Russian), Journal of Clinical laboratory diagnosis, no. 11, pp. 10-11, 2006.

18.B.S. Nagoev, M.H. Nagoeva, "The state of indices of prooxidant and antioxidant system in the ill with bacterial angina" (in Russian), Journal of Epidemiology and Infectious Diseases, no. 5, pp. 49-53, 2008.

19.L.B. Okonenko, "Lipid peroxidation under salmonellosis" (in Russian), Journal of Microbiology and Epidemiology, no. 6, pp. 55-58, 1994.

20.L.V. Oleynik, T.A. Sokiro, E.M. Popova, T.I. Tarasyuk, O.I. Vishchur, "The state of oxidative-antioxidant homeostasis under experimental toxicoinfection" (in Russian), in Free radicals, antioxidants and health of animals, 2004. Proceedings. The International Scientific and Practical Conference, Voronezh, 2004, pp. 123-126.

21.V.F. Pavelkina, A.A. Erovichenkov, S.G. Pak, "Improvement of pathogenetic therapy under the diseases of bacterial etiology" (in Russian), Journal of Infectology, vol. 4, no. 3, pp. 67-75, 2012.

22.V.F. Pavelkina, R.Z. Almyasheva, N.P. Ampleeva, Yu.G. Uskova, "Toxic syndrome under salmonellosis and its correction" (in Russian), Journal of Practical Medicine, no. 7(83), pp. 54-58, 2014. 
23. Order of Ministry of Public Health of the RF dtd. June 19, 2003 № 267 "On Approving the rules for laboratory practice" (Registered in the Department of Justice of the RF June 7, 2003 No. 4809) (in Russian).

24.M.I. Retskiy, V.S. Buzlama, A.G. Shakhov, "The significance of antioxidant status in adaptive heterogeneity and immunological resistance of animals" (in Russian), in Actual problems of young animals' diseases in modern conditions, 2002. Proceedings. The International Scientific and Practical Conference. Voronezh, 2002, pp. 33-36.

25.M.I. Retskiy, S.V. Shabunin, G.N. Bliznetsova et al. Methodological regulations on the study of processes of free radical oxidation and system of organism antioxidant protection (in Russian), Voronezh, 2010..

26.M.A. Ryzhikova, D.M. Gabitova, S.V. Sibiryak, "Chemiluminescence methods in laboratory diagnostics" (in Russian), Journal of Clinical Laboratory Diagnostics, no. 11, pp. 3-4, 2001.

27.A.A. Ryzhov, Yu.M. Kozlov, V.V. Petrov, "Method for the treatment and prophylaxis of free radical pathology in animals" (in Russian), Journal of Proceedings of UO VGAVM. vol. 43, issue 1, pp. 203-206, 2007.

28.M.A. Sidorov, V.V. Subbotin, V.V. Kudryavtsev, V.T. Stolyarenko et al., "Salmonellosis at stockbreeding complex" (in Russian), Journal of Pig Breeding, no. 3, pp. 29, 1991.

29.V.V. Subbotin, M.A. Sidorov, M.N. Loshchinin, "To the question on a possibility of intraintestinal immunization of pigs with inactivated preparations against salmonellosis" in Actual problems of infectious pathology and immunology of animals, 2006. Proceedings. The International Scientific and Practical Conference. - Moscow, 2006, pp. 139-141.

30.SC 2.2.1.3218-14 dtd. August 29, 2014 №51 "Sanitary-epidemiological requirements to arrangement, equipment and keeping of experimental-biological clinics (vivaria)".

31.E.Yu. Tarasova, Finding the methods for the treatment of animals under T-2 mycotoxicosis: abstract of a thesis, candidate of biological sciences (in Russian), Kazan, 2010.

32.V.I. Fisinin, Peter Surai, "Mycotoxins and antioxidants: irreconcilable struggle (T-2 toxin - mechanisms of toxicity and protection)" (in Russian), Journal of Poultry and Poultry Products, no. 3, pp. 36-39, 2012.

33.V.H. Havinson, V.A. Barinov, A.V. Arutyunyan, V.V. Malinin, Free radical oxidation and aging (in Russian), St. Petersburg, 2003.

34.A.G. Shakhov, "The role of free radical oxidation of lipids in pathogenesis of infectious diseases" (in Russian) in Free radicals, antioxidants and health of animals, 2004. Proceedings. The International Scientific and Practical Conference, Voronezh, 2004, pp. 3-9.

35.A.G. Shakhov, "Achievements and main directions of studying the diseases of young farm animals" (in Russian) in Actual problems of young animals' diseases in modern conditions, 2008. Proceedings. The International Scientific and Practical Conference. Voronezh, 2008, pp. 3-12.

36.A.G. Shakhov, L.Yu. Sashnina, Yu.N. Masyanov, G.A. Vostroilova, T.A. Erina, Hemomorphological and immune status under experimental infection of albino rats caused by Salmonella cholerae suis (in Russian) Main epizootological parameters of animal population: Collection of scientific papers of FGBOU VPO NGSHA, represented at the 2 nd session of the International scientific and practical conference "Population health of animals and emergent infections in modern conditions". Edited by V.V. Sochnev. Nizhny Novgorod, 2015. - Part 1. - pp. 499-506.

37.A.G. Shakhov, L.Yu. Sashnina, Yu.N. Masyanov, G.A. Vostroilova, "The changes of cytokine profile in albino rats under the effect of salmonellae against the background of subacute T-2 toxicosis" (in Russian), Journal of Russian Agricultural Sciences, no. 3-4, pp. 50-53, 2016.

38.A.G. Shakhov, L.Yu. Sashnina, G.A. Vostroilova, D.A. Lagutkin, A.E. Chernitskiy, "Correlation of cytokine profile and oxidant-antioxidant status of albino rats under experimental T-2 toxicosis" (in Russian), Journal of Veterinary Medicine of Kuban, no. 1, pp. 15-18, 2016.

39.V.I. Yunkerov, S.G. Grigoryev, Mathematical and statistical manipulation of medical studies data, St. Petersburg: VMedA, 2002.

40.J.E. Dvorska and P.F. Surai, "Effects of T-2 Toxin, Zeolite and Mycosorb on Antioxidant Systems of Growing Quail" Asian-Aust. J. Anim. Sci., vol. 14, no. 12, pp. 1752-1757, 2001.

41.M. Gilca, I. Stoian, V. Atanasiu, B. Virgolici. "The oxidative hypothesis of senescence", J Postgrad Med, 2007; 53:207-13.

42.D. Hoehler and R.R. Marquardt, "Influence of vitamins E and C on the toxic effects of ochratoxin A and T-2 toxin in chicks", Journal Poult. Sci. 75:1508-1515, 1996. 
43.D. Hoehler A.R. McIntosh, S. Madhyastha, "Free radical-mediated lipid peroxidation induced by T-2 toxin in yeast (Kluyveromyces marxianus)", J. Nutr. Biochem. no. 9, pp. 370-379, 1998.

44.Leeson, S., G. Diaz and J.D. Summers. Poultry metabolic Disorders and Mycotoxins. University Books. Guelph, Canada, 1995.

45.P.S. Martins, E.G. Kallas, M.C. Neto, M.A.Dalboni, S. Blecher, R. Salomão, "Upregulation of reactive oxygen species generation and phagocytosis, and increased apoptosis in human neutrophils during severe sepsis and septic shock", Shock, Sep; 20(3):208-12. 2003.

46.H.X. Nguyen, T.J. O'Barr, A.J. Anderson, "Polymorphonuclear leukocytes promote neurotoxicity through release of matrix metalloproteinases, reactive oxygen species, and TNF-alpha", J Neurochem, 102:900-12, 2007.

47.L. Papatheodorou, N. Weiss, "Vascular oxidant stress and inflammation in hyperhomocysteinemia", Antioxid. Redox Signal, no. 9, pp. 1941-1958, 2007.

48.Surai P.F. Selenium in Nutrition and Health. Nottingham University Press, UK, 2006.

49.V. Vandenbroucke, "Double trouble: interactions between deoxynivalenol and the pathogenesis of Salmonella typhimurium infections in pigs". Merelbeke: Ghent University. Faculty of Veterinary Medicine, 2012.

50.V. Vandenbroucke, S. Croubels, A. Martel, E. Verbrugghe, J. Goossens, K. Van Deun, F. Boyen, F. Thompson, N. Shearer, P. De Backer, F. Haesebrouck, F. Pasmans, "The mycotoxin deoxynivalenol potentiates intestinal inflammation by Salmonella typhimurium in porcine ileal loops", PLoS ONE , vol. 6(8), pp. 1-8, 2011. - doi: 10.1371/journal.pone.0023871. 